\title{
periferio
}

\section{TEMPO DE UMA NOVA VIDA E ESPAÇO DA RESISTÊNCIA: UMA EXPERIÊNCIA ENTRE GESTANTES E PUÉRPERAS DO PREVENTÓRIO COM A FRENTE DE SAÚDE POPULAR DO MTST}

Karina Caetano ${ }^{1}$

Universidade do Estado do Rio de Janeiro - UERJ

\section{Resumo}

Este artigo nasce do encontro da pesquisadora com o grupo Mães do MTST, no Morro do Preventório, RJ; vinculado a Frente de Saúde Popular do movimento e ao projeto de extensão Liga Multiprofissional de Saúde da Família/UFF. As atividades articulam múltiplos sujeitos e coloca saberes populares, femininos e favelados em diálogo com conhecimentos médicos e acadêmicos. A partir da educação popular em saúde, tempo, espaço e sujeitos são (re)pensados para compreender coletivamente como as participantes entendem a si, a maternagem e seus direitos. Objetivamos analisar como elas se organizam no território e como vivem o período da gestação junto desse processo educativo, fazendo: 1) Breve histórico do MTST, Grupo de Gestantes e Preventório; 2) Apresentando brevemete a atuação da Frente de Saúde no território.

Palavras-chave: grupo de gestantes; MTST; preventório; tempo; território

\footnotetext{
1 Mestranda do Programa de Pós-Graduação em Educação, Cultura e Comunicação em Periferias Urbanas - FEBF/UERJ. Colaboradora no projeto de extensão Frente de Saúde Popular do MTST. Professora de filosofia, doula e feminista. Pesquisa a relação entre educação popular de mulheres e a humanização do parto e nascimento desde 2008. karinacaetanos@gmail.com
} 


\title{
periferio
}

\author{
TIME FOR A NEW LIFE AND A SPACE FOR RESISTANCE: AN \\ EXPERIENCE BETWEEN PREGNANT WOMEN AND THOSE WHO \\ HAVE RECENTLY GIVEN BIRTH IN PREVENTÓRIO WITH THE FRONT \\ OF POPULAR HEALTH CARE OF MTST
}

\section{Abstract}

This research is based on the researcher's meeting with the pregnant women group Mães do MTST, in Preventório, RJ. Linked to the Front of Popular Health Care of MTST and to the Multiprofessional Health Family League - an extension project at UFF. A field that articulates multiple subjects and displays popular, feminine and favela's knowledge in dialogue with medical and academic knowledge. By popular education in health, time, space and subjects are (re) thought to understand collectively how the participants understand themselves, the mothering and their rights. We aim to analyze how they are organized in the territory and how they live the course of pregnancy next to this educational process, by presenting: 1) Brief history of the MTST, the Pregnant Women Group and Preventório ; 2) Analyzing the work of the Front of Health in the territory.

Keywords: group of pregnant women; MTST; preventório; time; territory 


\section{periferio}

\section{INTRODUÇÃO}

O acesso à educação e à saúde de qualidade, embora esteja formalizado como direito na Constituição de 1988, ainda situa-se entre as demandas que as classes populares, historicamente, reivindicam (BRASIL, 2013). Nesse contexto, os esforços de efetivá-lo respeitando as peculiaridades de cada população é uma proposta da educação popular em saúde ${ }^{2}$. Entre muitas iniciativas nesse campo, destaco o trabalho da Frente de Saúde Popular, uma parceria entre Movimento dos Trabalhadores Sem Teto (MTST) e Liga Multidisciplinar de Saúde da Família (LISF), formada majoritariamente por acadêmicas/os e profissionais médicas/os da Universidade Federal Fluminense (UFF). Deste encontro, foi possível realizar uma atividade no Cano Furado, São Gonçalo, RJ, com plantas medicinais e uma atividade no Morro do Preventório, Niterói, RJ, com o grupo de apoio Mães do MTST, contexto que propomos discutir neste artigo.

Tempo, espaço e sujeitos são três categorias especialmente caras à educação popular, devido as suas reivindicações e intervenções com e nas classes trabalhadoras e seus direitos. Ao trazer outras possibilidades de articulação, o tempo descola-se da perspectiva linear, herdada da tradição positivista; e é possível articular um tempo que espera a escuta acontecer, os sujeitos se reconhecerem, o processo educativo entrar em curso e fazer sentido cada uma delas (e também para nós). Ou para reinscrever o tempo no ciclo gerador de vida, durante o período gestacional, período de participação de uma mulher no Grupo (e que pode se estender).

Durante a gestação, a categoria tempo adquiri um matiz especial. Por até 42 semanas, é possível nascer uma nova vida! Uma espera permeada por incertezas, ansiedades e medos. Esse período é marcado por intensas

2 A educação popular em saúde a partir da troca de saberes ancestrais, populares e acadêmicos busca promover entre estudantes e profissionais da saúde a reflexão e reposicionamento sobre suas práticas, bem como auxiliar as usuárias/os a construir processos de autocuidado e autonomia que lhes possibilite a tomada esclarecida de decisões no âmbito da saúde. 


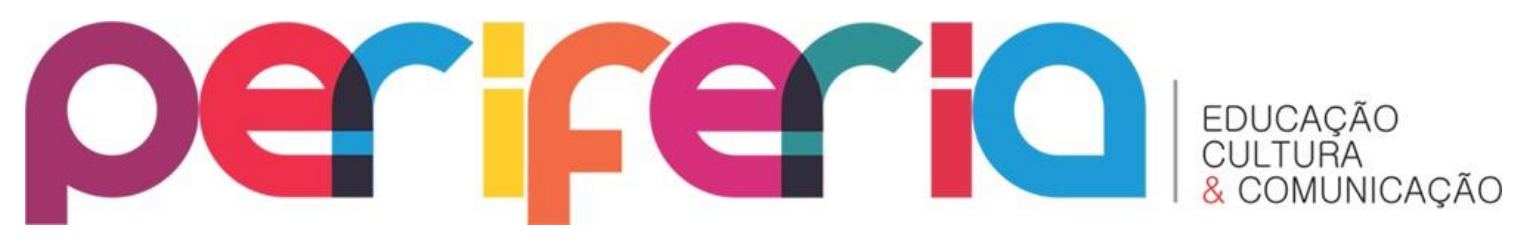

mudanças psíquicas, físicas e sociais apresentando à mulher múltiplas demandas e expectativas. Deste modo, manifesta-se a importância de grupos de apoio e acolhimento, no decurso da gestação e puerpério. Estes ultrapassam os cuidados estabelecidos no pré-natal, geralmente restritos aos aspectos físicos da mãe e do bebê (MURTA, 2014). Poder trocar experiências, reconhecer-se em outras mães e compreender as mudanças por que passa é o que torna os grupos de gestantes tão importantes.

O tempo gestacional é um importante mecanismo para elaboração da maternidade na mulher, para preparação do parto e dos cuidados com o bebê. No entanto, do ponto de vista da educação popular em saúde, o período junto ao Mães do MTST que pode durar por até um ano e meio se apresenta como um desafio. É necessário criar vínculos, desenvolver uma linguagem que comunique e ainda respeitar o tempo de aprendizado delas, que muitas vezes não conseguem comparecer devido a intercorrências com a gestante ou com o bebê.

O espaço, por sua vez, apresenta-se também de outras formas. A educação e saúde populares compreendem a potencialidade de estar no território para fortalecer o laço entre as pessoas; assim como para ampliar a sensação de pertencimento ao chão que pisam e o desejo de transformação deste. O território também é compreendido como um espaço a ser ocupado, para poder viver próprios de vida como pessoas portadoras de direitos. Espaços que precisam existir de modo equânime para cada pessoa. Aliás, a ocupação de espaços é uma atividade que centra as ações do MTST ao reivindicar o direito a cidade, a moradia e a vida com dignidade (BOULOS, 2014; GOULART, 2011).

Realizamos os encontros do Mães do MTST quinzenalmente, no morro do Preventório, Niterói, RJ. Além disso, ocupamos locais públicos como praças, museus e parques para realizarmos sessões de fotos das gestantes. Ocupar esses espaços visa tanto reafirmar às mulheres que estes também pertencem a elas, bem como lembrar à sociedade que essas grávidas existem e precisam viver suas gestações com liberdade, respeito e segurança. 


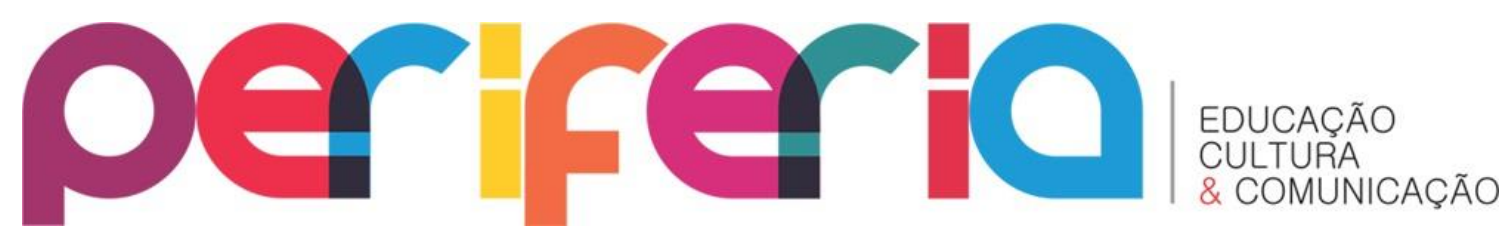

Por fim, os sujeitos da pesquisa e extensão possuem marcadores sociais bem delimitados, a saber: mulheres pobres, com baixa instrução, majoritariamente negras, gestantes e puérperas. Mães que sofrem com um sistema de saúde que não as respeita, por isto buscam no Grupo um ambiente de acolhimento e de trocas de experiências diante de suas demandas psíquicas e corporais. Aliás, chamá-las de sujeitos nos causa um grande estranhamento visto que são mulheres. A necessidade de utilizar essa categoria reafirma o quanto os paradigmas científicos ainda estão embasados em fundamentos patriarcais. Por que não nomeá-las de modo a respeitar o gênero de maior parte das participantes? Somos sujeitas!

Cientes que todo recolhimento de dados é uma relação socialmente elaborada, localizada, parcial, temporal... O que torna tão importante o esforço para apresentar o contexto, a escala e o cruzamento de informações. Acreditamos que o conhecimento científico deve ser metodologicamente plural fazendo da polifonia um recurso disparador para abarcar a complexidade do fenômeno estudado.

Situar não só o campo, mas, também, a pesquisadora na produção do conhecimento aponta para uma ciência que reconhece os lugares de fala diante da divisão desigual do saber. Desta maneira, o MTST, a LISF, a Frente de Saúde, o Grupo de Gestantes e Morro Preventório serão apresentados para que diante desse amálgama possamos entender de onde parte esta pesquisa. Optamos por utilizar como fontes principais para esta subseção relatos e conhecimentos produzidos pelas e pelos moradores e ex-moradores do Preventório, assim como das e dos militantes do MTST e estudantes de medicina.

\section{“A GENTE ORGANIZA O POVO” - BREVE HISTÓRICO DO MTST}

Valter Carlos Cruz (2010) destaca como os conceitos ganham sentido a partir de seu uso, podendo ser concebidos como ferramentas. Por isso, podemos falar de referencial teórico-metodológico a fim de indicar como a 


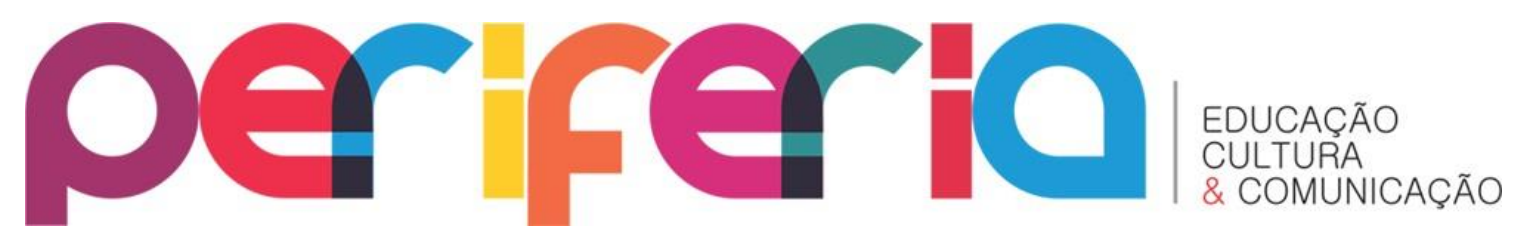

conceituação se articula com a empiria e perceber o conceito enquanto um processo social, histórico e territorializado. Ignorar essas dimensões pode nos fazer incorrer em anacronismos e produzir um conhecimento que não se situa no chão que pisamos. "É por isso que o conceito pode ser ferramenta tanto de conservação como de transformação. O conceito é sempre uma intervenção no mundo, seja para conservá-lo, seja para mudá-lo". (CRUZ, 2010, p. 06 apud GALLO, 2008. p. 35-36). As crescentes lutas por direitos ${ }^{3}$ empreendidas pelas mulheres nos ajudam a compreender esse fenômeno: pois, à medida que é possível nomear diversas violências antes invisibilizadas, a luta se fortalece e os mecanismos jurídicos, políticos e sociais são obrigados a repensar e promover soluções para essas questões, que ganham força também pela via conceitual.

O crescimento das cidades e a implementação do Código de Obras (1937), a partir da década de 1940, passa a retirar os trabalhadores dos centros e os deslocar para as margens da cidade (VALLE, 2014). Longe dos centros e sem estrutura estas pessoas vêm sendo obrigadas a viver em situações desumanas à medida que direitos se transformam em mercadoria e em privilégio. Enquanto estes trabalhadores precisam pagar pelo loteamento, pelos materiais para construção ou pelo transporte público de localidades demasiado distantes para chegar aos seus trabalhos (BOULOS, 2014); os especuladores, loteadores e construtores fazem riqueza com venda dos lotes, com a valorização dos terrenos intermediários e das áreas centrais ampliando o abismo entre ricos e pobres e déficit habitacional.

Discutir o déficit habitacional no Brasil, com famílias sem-teto, em condições degradantes de moradia ou com despesas de aluguel muito altas, é debater a própria formação das periferias das cidades brasileiras percebendo o quanto as populações pobres são historicamente marginalizadas.

3 Outras lutas como as do MST (Movimento Sem-Terra) ou do Movimento Negro também nos ajudam a repensar conceitos como periferia, classe ou transformação social. 


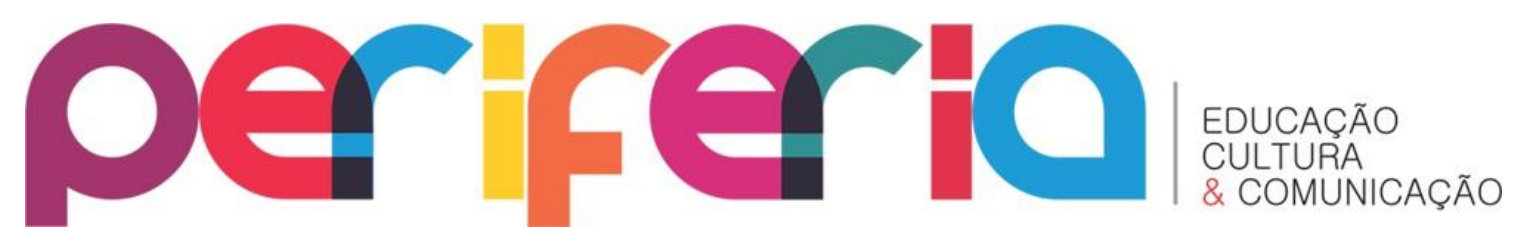

O último estudo feito pela Fundação João Pinheiro (publicado em novembro de 2013), que é utilizado oficialmente pelo Governo, mostra que o déficit habitacional quantitativo no Brasil é de 6.940.691 famílias, o que representa cerca de 22 milhões de pessoas que não tem casa. Os sem-teto são, portanto, mais de 10\% da população do país (BOULOS, 2014, p. 14).

Este dado inscreve apenas o déficit habitacional quantitativo, sendo que o qualitativo, daquelas pessoas que vivem sem condições para uma vida digna com acesso a água, saneamento básico e luz é ainda maior. A título de exemplo, "A região metropolitana do Rio de Janeiro tem mais de 700.000 famílias nesta condição" (BOULOS, 2014, p. 14).

Da constatação e não aceitação desse déficit nasce o MTST. A primeira notícia que temos sobre este Movimento aparece no III Encontro Nacional do MST, em 1995, com intenção ampliar as lutas da reforma agrária para o meio urbano. Durante a Marcha Nacional do MST, em 1997, é possível aglutinar forças por meio do diálogo com movimentos urbanos de moradia que atuavam de modo isolado. No mesmo ano, em Campinas, SP, o MTST organiza sua primeira ocupação no parque Oziel. "Sem água e esgoto, luz e serviço de coleta de lixo, o local reuniu, inicialmente, 200 famílias, mas, em menos de quatro meses, esse total já alcançava o admirável número de 4500 famílias" (GOULART, 2011, p.21). Na época, ambos os movimentos precisavam aprender a lidar com os problemas das periferias urbanas: polícia, comércio de drogas, facções, etc.

Débora Goulart (2011), em sua tese sobre o início do MTST e sua luta anticapitalista, aponta para complexidade de investigar a história dos movimentos sociais, seus avanços, recuos e os múltiplos atores sociais. Para ela há indícios da "presença do MTST na região de Campinas desde o ano de 1996, quando militantes do MST auxiliaram na organização de ocupações de terrenos realizadas de maneira espontânea" (GOULART, 2011, p.18).

Em 1997, o MTST chega ao Rio de Janeiro com a vinda de militantes do Parque Oziel. Sendo sua primeira ocupação ocorrida em 1998, na Av. Brasil. 


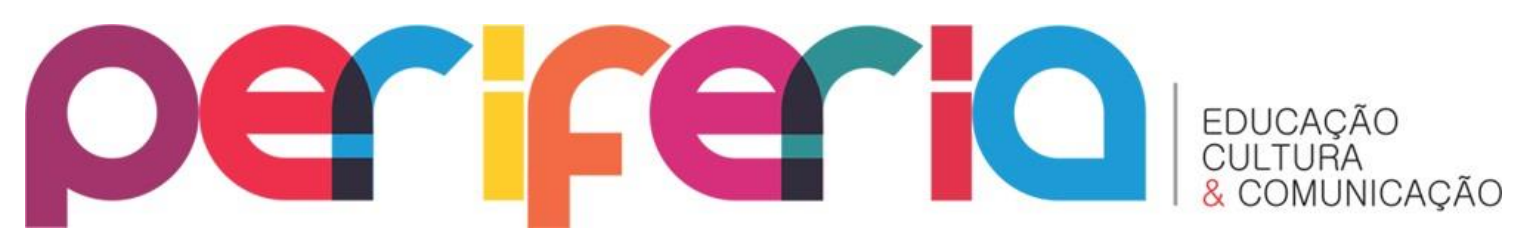

Embora em 1999 tenha conseguido assentar 2001 famílias na região de Sepetiba, Nova Iguaçu e Bangu, após essa conquista e seguidas ameaças de morte a militantes o movimento se desarticulou (GOULART, 2011).

Em maio de 2009, depois de muita reflexão sobre suas práticas, avanços e recuos no estado de São Paulo, o movimento decide lutar no interior do estado e se nacionalizar. Surgem outros grupos sob uma mesma organização nacional tendo como pauta principal "a inclusão do movimento, como entidade organizadora de projetos habitacionais, no programa "Minha Casa, Minha Vida" e "a participação ativa do Governo Federal nas negociações do MTST em todas as regiões e estados onde o MTST está presente" (GOULART, 2011, p. 56 apud MTST, 2009) demandas atendidas no mesmo ano pelo Ministério das Cidades.

No Rio de Janeiro, destacamos a ocupação de 07 de agosto de 2015, em Niterói, quando cerca de 200 famílias organizadas pelo MTST, ocuparam um terreno no Largo da Batalha, no início da Estrada Francisco da Cruz Nunes (MTST, 2015). Das vivências e assembleias dessa ocupação e da ocupação 06 de abril de 2010 - São Gonçalo é que nasce a Frente de Saúde, e posteriormente, o grupo Mães do MTST. Atualmente o MTST conta com cerca de 300 famílias organizadas que participam de assembleias mensais enquanto aguardam o avanço das negociações com o Governo.

A luta territorial ultrapassa a questão da moradia, por isso o MTST busca garantir outros direitos como educação, saneamento básico, saúde e cultura para população pobre; conforme relato da coordenadora Ana, em sua fala durante nosso Chá de Bebê Coletivo:

Aí chegamo lá posto, de frente a ocupação e entramo. ... Uns médico correndo pra lá, outros médico correndo pra cá. Sei que tiveram que atender a gente. Aí o prontuário era um prontuário só, pra todo mundo. Mil famílias tinha um prontuário só, que era a pasta do Zumbi dos Palmares, neh. Aí, depois fizeram até um prontuário pra cada família. A gente organiza o povo. Então se a demanda é casa, a gente faz luta por casa, tamo lá no terreno, lá com nossos barraquinho no 


\section{periferio}

terreno. Aí se a demanda é escola, a escola num ta tratando a gente bem, a gente vai na escola (ANA, 04 de dezembro de 2016 [grifo nosso]).

Uma das estratégias para tal empreitada diante de um Estado comprometido com a iniciativa privada é a criação de Frentes nos espaços do movimento. As Frentes possibilitam a colaboração entre MTST e outros coletivos e indivíduos visando melhorar as condições de vida das famílias semteto.

\section{“Aí EU PEDI PRA FAZER ALGUMA COISA PELA GENTE" - MÃES DO MTST}

Os primeiros passos para construção do grupo ocorreram com a ocupação 06 de abril de 2010 - São Gonçalo, em agosto de 2015, por meio da criação de uma farmácia com fitoterápicos e alopáticos gerida por militantes, estudantes e profissionais médicos da UFF. Depois, também foi estabelecido um espaço de repouso, escuta e pequenos atendimentos. Durante a construção dos barracos, foi observada a necessidade de trabalhar de modo preventivo contra insolação e desidratação por meio da distribuição de água e protetor solar. Do contato cotidiano, foram partilhadas as tarefas de distribuição e confecção de chás medicinais. Desse diálogo e da aplicação de questionários pelo Movimento culminou na criação da Frente de Saúde Popular no mesmo ano.

$\mathrm{Na}$ assembleia do mês de agosto, ocorrida na ocupação no Largo da Batalha - Niterói, o MTST iniciou a discussão para desenvolver uma atividade que atendesse as gestantes. A mulher negra, ocupante e moradora do Preventório, Tati, narrou durante o terceiro Chá de Bebê Coletivo, em 04 de dezembro de 2016, como ela percebeu a demanda: "Eu tava grávida neh. As grávida tavam abandonada, tem muita grávida nova, que num sabe o que fazer com o filho. E essas mulher precisa de atenção e de ajuda. Aí eu pedi pra fazer alguma coisa pela gente". Diante dessa demanda e das questões que se apresentavam sobre pré-natal e parto, além de inúmeros relatos de 


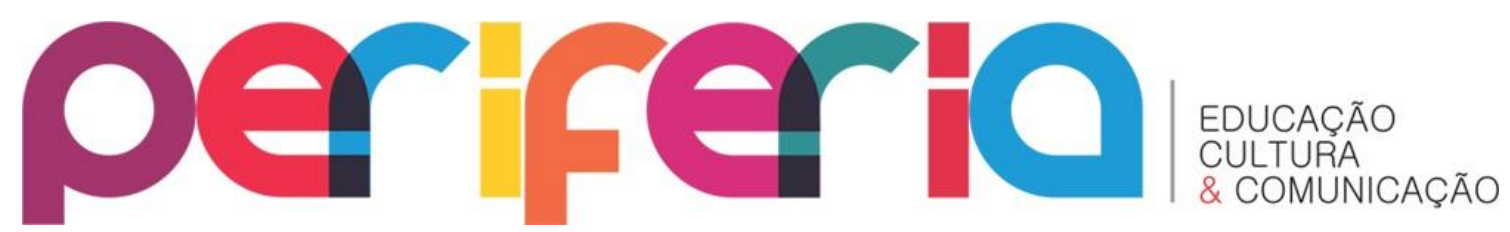

violência obstétrica criou-se Frente Saúde da Mulher: Direitos sexuais, reprodutivos e durante a gestação. Com o passar do tempo ela passou a ser nomeada apenas como grupo Mães do MTST.

O primeiro encontro do grupo ocorreu no dia 27 de setembro de 2015, na Praça de São Francisco - Niterói. Conforme relato de Gabi (04 de janeiro de 2017), uma das principais facilitadoras:

O primeiro encontro foi uma apresentação ao grupo, todas se apresentaram e foi explicado como ia funcionar os encontros (na época não tinha os planos de chá, e as mulheres, em grande parte, foram convidadas em unidades de saúde: deixamos alguns panfletos nas unidades do Preventório e do Caramujo e nas assembleias do Movimento, com o convite do encontro e para as fotografias). (...) E nesse primeiro grupo, também íamos construindo os álbuns de fotografia ao longo do grupo, um domingo tirávamos as fotos e no outro levávamos impressas pra colarem no álbum e escrevíamos algumas reflexões.

Com o passar do tempo, a dinâmica do Grupo foi se redesenhando. Atualmente, as mulheres propõem o tema a ser debatido. Este é discutido e avaliado pelas facilitadoras (es), no intuito de organizar as demandas de cada encontro. Trazer o tema gerador das demandas das próprias mulheres é uma forma de reconhecer seus saberes e fazer com que elas sejam parte, não como pacientes, mas produtoras de saberes (BRANDÃO e ASSUMPÇÃO, 2009). Mesmo após puerpério elas ainda encontram no Mães do MTST uma referência para pautar suas dúvidas e trocar com as redes de mulheres que se formam. Conforme relato da Michele, em 30 de novembro de 2016: "Eu continuei conversando com vocês pelo Whatsapp, neh. Eu dei idéias do que podia ser discutido nos encontros neh. (...) E pra mim eu tava participando normalmente. Meu filho nasceu, mas eu continuava no Grupo. Eu me sentia parte”.

Esta metodologia cumpre o objetivo geral do projeto, de acordo com o portal Sigroj1.mec: "Construir a partir da Saúde da Família e da Educação 


\section{periferio}

Popular em Saúde, processos de diálogo, vivência e reflexão crítica sobre saúde, autonomia e transformação social" (JUNIOR, 2015, p. 07).

Desde o setembro de 2015, os encontros ocorrem quinzenalmente e ao fim de cada semestre a formação é celebrada com um Chá de Bebê Coletivo. Já foram discutidos temas relativos aos Sentimentos das mães; cuidados com mãe e bebê; emergências puerperais; cor, raça, beleza e fotografia; os dilemas das mulheres das periferias; transformações mãe e bebê, atenção a gestante e mãe no mundo sexista; direitos das mulheres; entre outros temas relativos à maternidade e transformação social.

\section{PREVENTÓRIO - UMA HISTÓRIA DE OCUPAÇÃO E REMOÇÕES}

Milton Santos (2012, p. 25) nos alerta que "nenhuma sociedade tem funções permanentes, nem um nível de forças produtivas fixos, nenhuma é marcada por formas definitivas de propriedade, de relações sociais". Diante dessa compreensão das irremediáveis transformações por que passa uma sociedade retomamos a história do Morro do Preventório, no Bairro Charitas, em Niterói. Desde 1851 a principal construção da região abrigava doentes, vindos da capital do império, contagiados por febre amarela, cólera e varíola, no Hospital da Enseada de Jurujuba. Com o declínio destas doenças, a partir de 1909 o hospital passou a chamar Preventório Paula Cândido que recebia crianças que se preveniam da tuberculose (NETO, 2013). A comunidade foi criada por pescadores, funcionários do hospital e seus parentes que passaram a viver no entorno da instituição de saúde (RIO DE JANEIRO, 2008). As funções do hospital, bem como do Morro se transformaram restando apenas o nome de um território que já foi símbolo de cuidado na área da saúde e que hoje tem esse direito precarizado, sendo a principal reclamação das participantes. Conforme relato de Mari, em 04 de dezembro de 2016: "Eu me senti abandonada. (...) Eu tava sentindo muito dor e pedi pra eles me operar, mas eles não queria. Aí vinha um monte de gente me dar toque, toque, toque. 


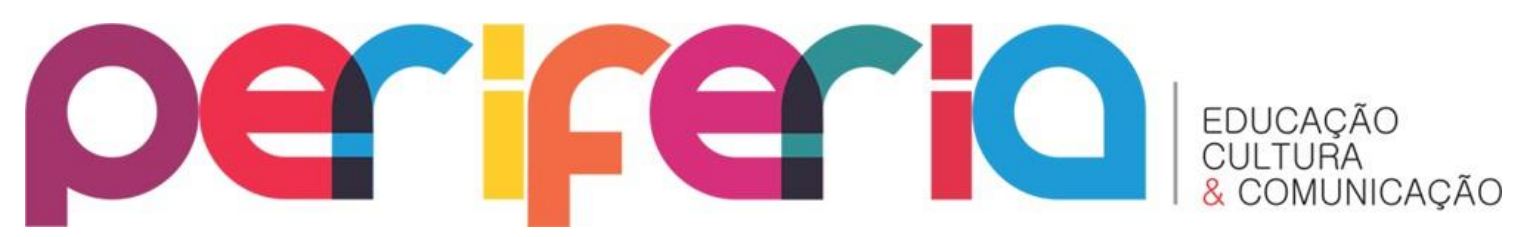

Acho que eu recebi uns dez toque ali. (...) Eu queria que fosse muito melhor a maternidade".

Outro cenário que se transforma no Preventório, se vincula a especulação, os despejos e os valores dos aluguéis que expulsam os moradores para regiões cada vez mais distantes.

Quando os trabalhadores insistem em morar em lugares valorizados, através de ocupações antigas, os capitalistas pressionam o Estado para despejar a comunidade. Sempre que consegue vencer a resistência dos moradores, o Estado despeja. E, quando muito, oferece conjuntos habitacionais nas áreas mais periféricas (BOULOS, 2014, p. 33).

A cena narrada por Guilherme Boulos (2014), uma das principais lideranças do MTST, se repete como uma ladainha nas periferias, o que não é diferente no Morro do Preventório. Segundo a Secretaria de Obras do Estado (2008) as famílias foram removidas para construção de um túnel que vai ligar Charitas x Cafubá, inaugurado em 2017, e para reflorestamento de áreas de proteção ambiental. Pessoas que perderam seus vínculos e histórias de uma vida inteira e foram realocadas em um conjunto habitacional no início do Morro, conforme relato de Dona Graça, em 24 de novembro de 2016, quando falava de sua remoção do Morro para os apartamentos do PAC: "Eu tinha muito orgulho da minha casinha, foi a primeira com laje lá de cima. Eu tinha medo que acertassem minhas filhinhas, que alguém jogasse uma pedra no telhado e acertasse elas. Aqui no PAC também tá bom. Mas lá era melhor, eu sinto saudade de lá". Atualmente, as e os residentes do Preventório vivem em clima de constantes incertezas em um território que sofre fortemente com a especulação imobiliária. Moradores e comerciantes locais também foram removidos da praia de São Francisco para construção da estação das barcas. Esse fator faz com que a organização da população a partir de ideais do MTST se justifique e se torne cada vez mais fortes. 


\section{periferio}

\section{ESPAÇO DA RESISTÊNCIA: A QUESTÃO TERRITORIAL NO MORRO DO PREVENTÓRIO}

Milton Santos (2012) evidencia a necessidade de situarmos a análise, isto é, não nos voltarmos às sociedades em geral, mas atentarmos a uma sociedade específica onde espaço e tempo dão as coordenadas para compreender um fenômeno único. Visto a especificidade de uma sociedade concreta e historicizada o território é uma categoria fundamental para se preparar cada ação. Do mesmo modo, ele também é uma categoria cara ao MTST. "Assim, o espaço em que milhões de trabalhadores no Brasil e em outros países tem se organizado e lutado é o território. É aí que o MTST se localiza: Somos um movimento territorial dos trabalhadores." (MTST, p. 04). Antes da ocupação de uma terra o Movimento reconhece o território, dialoga e convida a população se organizar na luta por direitos.

o espaço assim como o tempo, é social, sendo fundamental para compreender como o modo de produção interfere na estrutura social. "De fato, o espaço não é uma simples tela de fundo inerte e neutro" (SANTOS, 2012, p. 31). Essa questão se complexifica visto que as e os pesquisadores e extensionistas da Frente não são nascidos ou criados em Niterói. Todo coletivo atualmente é composto por cerca de dez pessoas vindas recentemente para a região, com intuito de estudar, trabalhar ou militar. A condição de forasteiros nos coloca uma demanda ainda maior no sentido de reconhecer 0 espaço, bem como tempo, as sujeitas (os) e suas significações para elaborarmos as atividades.

Por isso, antes de iniciar cada uma das atividades é feita a identificação dos territórios atuamos. "A partir das demandas surgidas no contato com a comunidade e nas atividades de Extensão, organizamos seminários, apresentações de grupo e oficinas temáticas, quinzenalmente. (JUNIOR, 2015, p. 09)". 


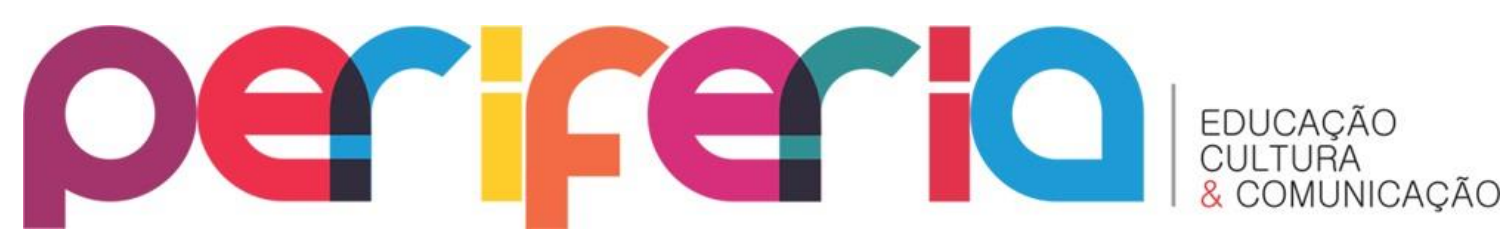

Doreen Massey (2000) nos convida a pensar o lugar complexificando-o e analisando-o a partir das relações que ali se estabelecem, das vivências que ali se efetivam, das pessoas que nele habitam.

\begin{abstract}
O que dá a um lugar sua especificidade não é uma história longa e internalizada, mas o fato de que ele se constrói a partir de uma constelação particular de relações sociais, que se encontram e se entrelaçam num locus particular. (...) Assim, em vez de pensar os lugares como áreas com fronteiras ao redor, pode-se imaginá-los como momentos em rebeldes de relações e entendimentos sociais, onde uma grande proporção dessas relações, experiências e entendimentos sociais se constroem numa escala maior do que costumávamos definir para esse momento como lugar em si (...). (MASSEY, 2000, p. 184).
\end{abstract}

Por isso, o território é vivo e suas fronteiras fluidas, suas identidades em disputa são múltiplas, e até, contraditórias.

Neste território em constante transformação, são recorrentes as reclamações relacionadas ao comércio de drogas, contexto que mudou o cotidiano do Morro. Segundo moradores, após a criação das Unidades de Polícia Pacificadora (UPP's) realizadas na capital do Rio de Janeiro, facções do crime organizado ocuparam a região modificando o cotidiano do Preventório (SILVA, 2011). A realidade de violência, ampliada pelo trato que as polícias fluminenses dedicam às favelas, cria um clima de insegurança e medo constantemente. As operações feitas por essas polícias em parceria com o Exército e Força Nacional agravam os quadros de violência e genocídio da população negra desses territórios. Esse cenário é exposto pelas gestantes que temem por suas famílias, conforme relato de uma gestante, que por questão de segurança não será identificada:

Aqui, hoje, é muito difícil. Eu quero meter o pé. Depois que [uma parente $\left.{ }^{4}\right]$ minha, grávida de sete messes foi

4 Por questões de segurança da gestante, o grau de parentesco entre ela e seus parentes vitimados e (co)produtores das violências no morro, foi suprimido 


\section{periferio}

morta e acharam ela lá em cima do Morro. Os menino achou que ela entregou eles. (...) Eu não quero ficar mais aqui, já morreu outros dois [parentes] meu também. Quero pegar minha filha e sair.

O crime relatado, que vitimou Thaila de Oliveira, aos 22 anos. Ela estava com 28 semanas de gestação, foi torturada pela polícia para dar informações sobre o comércio de drogas e morta pelo crime organizado (R7, 2011). Essa situação de terror evidencia a barbárie e guerra de pobres contra pobres, tão recorrente nas favelas brasileiras. Esse quadro complexifica nossa atuação no campo, ao ampliar a demanda das gestantes por acolhimento e impor limites a atuação do Movimento e da Frente.

Compreender tempo e espaço em que os sujeitos da pesquisa e da extensão estão vinculados nos auxilia a produzir um conhecimento coerente com as e os sujeitos envolvidos, a melhor compreender suas lutas, bem como fazer com que os conteúdos a serem trabalhados dialoguem com seus modos de vida. Estes sujeitos, mulheres pobres, moradoras da periferia de Niterói, mães e em sua maioria negras, são sabedoras dos desafios que terão para maternar suas crias em territórios onde direitos thes são negados e se transformam em privilégios.

Sabemos que quando trabalhamos com educação e saúde populares território e tempo se destacam para (re)conhecimento de cada pessoa. Não que morar na zona sul do Rio ou em outras áreas privilegiadas não defina as pessoas que lá habitam ou que estas não tenham história. Assim como não há denominação própria para quem vive no Sudeste, enquanto nordestinos carregam seus estigmas, o mesmo ocorre com a população pobre de muitas periferias: embora sejam muito distintas estão congregadas em um só nome em função do seu território: faveladas e favelados. Assim percebemos como a hegemonia encobre certas subjetividades naturalizando estas histórias e criminalizando outras o que torna tão importante situar as pessoas subalternalizadas. 


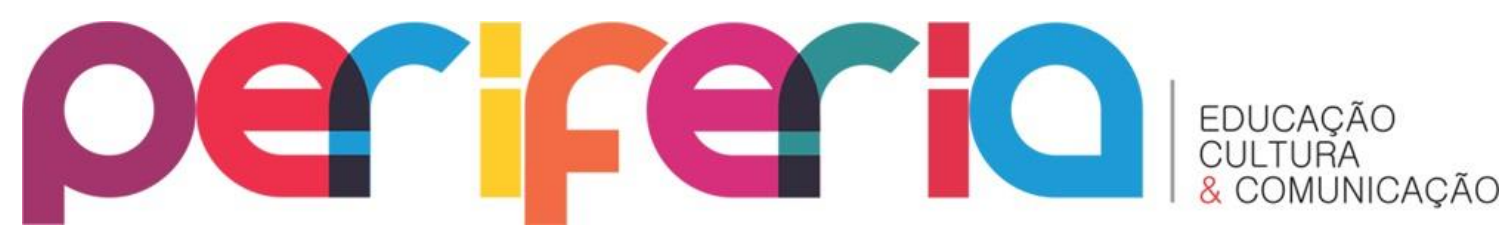

\section{REFERÊNCIAS}

BRANDÃO. C.; ASSUMPÇÃO, R. Cultura rebelde: escritos sobre educação popular ontem e agora. São Paulo: Editora e livraria instituto Paulo Freire, 2009

BRASIL. Ministério da Saúde. Cadernos de Atenção Básica, n. 29, Volume II, Ministério da Saúde, Secretaria de Atenção à Saúde Departamento de Atenção Básica, 2013.

BOULOS, G. Por que ocupamos. São Paulo: Editora Secci, 2014.

CRUZ, W. Uma proposta metolológica para o uso/operacionalização dos conceitos na pesquisa em geografia. In: ANAIS XVI ENCONTRO NACIONAL DOS GEÓGRAFOS, Porto Alegre, 2010.

JUNIOR, A. et al. Projeto de extensão: Liga Multiprofissional de Saúde da Família LISF . Brasília, 2015. Disponível em: $<$ http://sigproj1.mec.gov.br/projetos/imprimir.php?modalidade=0\&projeto_i d=223866\&local=home\&modo=1\&original=1 >. Acesso em: 05 fev. 2016.

MASSEY, D. Um sentido global do lugar. In: ARANTES, A. A. (ORG.) O Espaço da Diferença. Campinas: Papirus, 2000.

MOVIMENTO DOS TRABALHADORES SEM-TETO. Carta ao Presidente Lula. São Paulo, 2009. Disponível em: <http://www.mtst.info/?q=node\&page=2>. Acesso em: 15 ago. 2009.

MOVIMENTO DOS TRABALHADORES SEM-TETO. Niterói vai amanhecer vermelha. http://www.mtst.org: 2015. Disponível em:

http://www.mtst.org/mtst/niteroi-vai-amanhecer-vermelha/. Acesso em: 22 de dezembro de 2016.

MURTA, C. (org). Parthos - Filosofia Psicanálise Saúde da Mulher. Vitória: CRV, 2014.

NETO, E. As Práticas em Saúde Pública no Brasil (Niterói-RJ): o TERRITÓRIO e suas possibilidades. Niterói, 2013. Disponível em: <http://www.alass.org/cont/priv/calass/docs/2013/sesion29/3008_sesion29_1-pt.pdf>. Acesso em: $20 \mathrm{dez} .2016$.

RIO DE JANEIRO. Canteiro de Obras, n. 19. Rio de Janeiro: Secretaria de Estado de Obras, 2008. Disponível em: <http://download.rj.gov.br/documentos/10112/243527/DLFE29828.pdf/Boletim_Outubro_2008.pdf $>$. Acesso em: 13 dez. 2016.

SANTOS, M. Da Totalidade ao Lugar. São Paulo: EdUSP, 2012. 


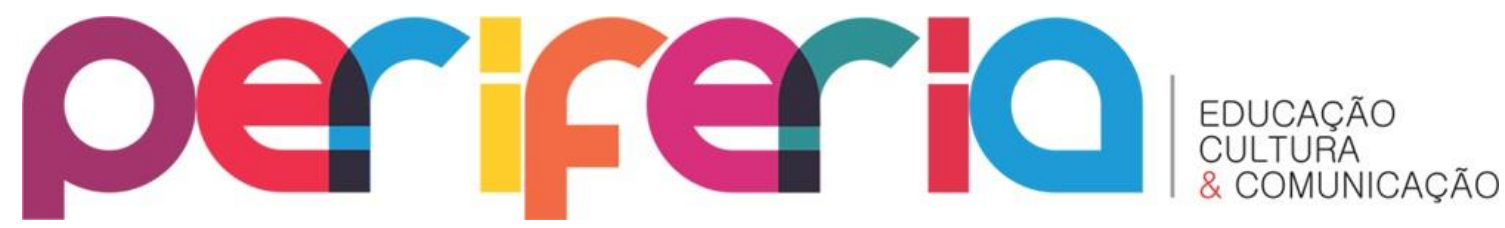

SILVA, A. Três opiniões de quem conhece de perto o morro do Preventório. Desabafos Niteroienses, Blog [INTERNET]. Niterói: Ana Paula da Silva, 2011. [Citado em 27 de março de 2011]. Disponível em:

$<$ http: //www.desabafosniteroienses.com.br/2011/03/tres-opinioes-de-quemconhece-de-perto.html>. Acesso em: 21 nov. 2016

VALLE, M. A favela que não cabia na fotografia: limites da representação.2014. 151f. Dissertação (Mestrado em Comunicação) Programa de Pós-Graduação em Comunicação, Universidade Federal Fluminense, Niterói. 2014. 